\title{
Biological and Clinicopathological Characteristics of Breast Cancer at Tikur Anbessa Specialized Hospital, Addis Ababa, Ethiopia
}

\section{Bizualem Shenkutie ${ }^{1}$, Yalemtsehay Mekonnen ${ }^{1}$, Daniel Seifu², Endegena Abebe ${ }^{3}$, Wondwossen Ergete ${ }^{4}$, Amanuel Damie ${ }^{4}$ and Wajana Lako} Labisso $^{4 *}$

${ }^{1}$ Department of Microbial, Cellular and Molecular Biology, College of Natural and Computational Sciences, Addis Ababa University, Addis Ababa, Ethiopia ${ }^{2}$ Department of Medical Biochemistry, College of Health Sciences, Addis Ababa University, Addis Ababa, Ethiopia

${ }^{3}$ Department of Physiology, College of Medicine and Health Sciences, Hawassa University, Hawassa, Ethiopia

${ }^{4}$ Department of Pathology, College of Health Sciences, Addis Ababa University, Addis Ababa, Ethiopia

\begin{abstract}
Breast cancer (BC) is one of the most heterogeneous types of cancer and is characterized by several molecular subtypes. Descriptive cross-sectional study was conducted on 137 confirmed BC cases at Tikur Anbessa Specialized Hospital (TASH) in Ethiopia from December 2015 to November 2016 to assess the biological and clinicopathological characteristics of BC in Ethiopian women patients. Socio-demographic characteristics of the study subjects was obtained with pretested structured interview and clinical data was collected from the Hospital records. Surgical specimens were analysed histopathologically with hematoxyline and eosin staining, and Immunohistochemistry analysis was conducted with specific antibodies to ER, PR and HER2. The mean and median age of the study participants were 47 and 46.7 , respectively. More than $50 \%$ of the patients were categorized in the age group of 15-40. Sixty percent were in the age group of 41-100. Infiltrating ductal carcinoma was the most common type of BC $(70 \%)$ in this study, followed by lobular carcinoma (8.5\%). Almost all of the BC cases under study were at advanced stage of the disease: $48.5 \%$ were with stage III and $51 \%$ were grade II tumors. Half of the study participants belonged to T2 tumor size $(2-5 \mathrm{~cm})$ and $52.3 \%$ of the patients had axillary lymph node metastases. Sixty five percent were ER+, $58 \%$ were PR+ and $28 \%$ were HER2+. Luminal A was the most common tumor subtype (54\%), followed by luminal B $(22 \%)$ and TNBC $(18 \%)$. Based on crude analysis, patients with family history of BC had a lesser likelihood of being ER+ as compared to those patients with no family history of BC [COR=0.10 ( $95 \% \mathrm{Cl}$ : $0.028,0.34)]$. None of the other risk factors were correlated with the prevalence of ER+ results. In conclusion, the age distribution of BC cases in this study suggests the need to create awareness and improvement of advanced diagnostic services and make available screening programs for younger people. In a resource poor setting like Ethiopia, the use of anti-estrogens (like tamoxifen) in treatment of BC cases with undetermined receptor status could be helpful as most BC cases are ER+ and hormonal therapy is relatively easily available.
\end{abstract}

Keywords: Breast cancer; Estrogen receptor; Human epidermal growth factor receptor 2; Progesterone receptor; Ethiopia

\section{Introduction}

Breast cancer (BC) is the most common malignant tumor in women across the globe, with approximately 1.6 million new cases diagnosed and over half a million-death reported each year [1,2]. It is clinically and molecularly heterogeneous disease with various malignant potential. Genetic and molecular analysis also indicate that breast cancer is characterized by diversified tumor biology, which in turn affects the predictive and prognostic value of the disease $[3,4]$. Moreover, the prognosis and survival rates for breast cancer patients depends on the molecular subtypes, stage of the disease, treatment modalities, and geographical location of the patient [5-9]. For example, the survival rate of $\mathrm{BC}$ is high in high income countries (HICs) compared to low income countries (LICs). The low survival rates of BC in LICs is partly attributed to the absence of screening programs and advanced diagnostic means like immunohistochemistry and molecular techniques. Absence of better treatment facilities and poor awareness of the public about breast cancer also contributes to the low survival rate in this region [10-12]. Breast cancer has got low attention and, still, the burden is extremely increasing in African countries, including Ethiopia [13]. The incidence is significantly lower in Eastern Africa with approximately 18,000 new cases each year. Unfortunately, the corresponding 10,000 mortality (more than 50\%) occur during the same year in Africa [14-16]. This is because most of the African breast cancer patients are presented with advanced stage of the disease where they cannot benefit from the currently available treatment approaches. The mean age of breast cancer patients in Africa is also significantly lower (48 years), from which approximately two-thirds are premenopausal [17]. This is awful compared to the 67 years median age in white British women [18]. It is also reported that the African-American women have also presented at a significantly younger age than their Caucasian counterparts [19]. These complex and versatile nature of breast cancer is partly due to variation in the genetic signature, tumor biology, dietary and life style of the people and other undermined environmental conditions [20-22]. Therefore, the outcome of breast cancer patients is the function of the characteristic nature of tumor biology and genetics profiles that are coupled with their corresponding modulating environments. As a result, clinical and pathological investigation of these factors before applying any treatment modalities will have great impact on the therapeutic outcome of the patients. Furthermore, it is very essential to determine the features of cancer cells, the expression

*Corresponding author: Wajana Lako Labisso, Department of Pathology, College of Health Sciences, Addis Ababa University, Addis Ababa, Ethiopia, Tel: 251911429050; Email: wajana.lako@aau.edu.et

Received November 30, 2017; Accepted December 27, 2017; Published December 29, 2017

Citation: Shenkutie B, Mekonnen Y, Seifu D, Abebe E, Ergete W, et al. (2017) Biological and Clinicopathological Characteristics of Breast Cancer at Tikur Anbessa Specialized Hospital, Addis Ababa, Ethiopia. J Cancer Sci Ther 9: 755760. doi:10.4172/1948-5956.1000504

Copyright: (c) 2017 Shenkutie B, et al. This is an open-access article distributed under the terms of the Creative Commons Attribution License, which permits unrestricted use, distribution, and reproduction in any medium, provided the original author and source are credited. 
of the playing proteins/gene and the clinico-pathological characteristics in width. These will help reveal a clear picture of the breast cancer in our community. The complex variations in tumor biology, clinical manifestation, treatment response and prognosis among different breast cancer patients in Ethiopia is poorly investigated. Moreover, Ethiopian people are characterized by complex cultural, linguistic and genetic profiles. Differences in the genetic profile could lead to dissimilarity in the predictive and prognostic values of the breast cancer patients. Therefore, the objective of this study was to explore the biological and clinicopathological characteristics of breast cancer in Ethiopian patients.

\section{Methods}

\section{Patients and study design}

This was a descriptive cross-sectional study conducted at TASH from December 2015 to November 2016. TASH is the largest teaching and referral hospital in the country receiving pathology specimens from all corners of the country. We applied 137 biopsy samples of breast cancer patients with histopathologically confirmed solid malignant tumor cases in this study. All cases under study were histopathologically classified using Chapter 11 Neoplasm, International Statistical Classification of Diseases and Related Health Problems 10 Revision (ICD-10)-WHO Version for; 2016) by experienced expert pathologist. Informed consent was obtained from study subjects to participate in this study. All male breast cancer patients and study subjects with age $<15$ years were excluded. In addition, study subjects with severe infection, active clinical co-morbidities, or a history of any other malignancy and those breast cancer patients with pregnancy and who were not willing to give informed consent were excluded. This study was reviewed and approved by Addis Ababa University, the College of Natural and Computational Sciences and College of Health Sciences Institutional Review Board (IRB) committee.

\section{Histopathology}

Breast cancer surgical specimens were washed with PBS, fixed in Roti $^{\oplus}$ Histofix for 24 hrs, dehydrated using ASP300 Tissue Processor (Leica) and embedded in paraffin. A series of $4 \mu \mathrm{m}$ thick sections were cut for Hematoxylin and Eosin (H\&E) staining. Wax was removed from paraffin embedded tissue sections with the aid of $2 \mathrm{x}$ Roti ${ }^{\bullet}$ Histol (Carl Roth) for 5 minutes. Then, the tissue was rehydrated with the decreasing alcohol series ( $2 \times 100 \%, 2 \times 98 \%$ and $2 \times 80 \% \mathrm{EtOH})$, each for 3 minutes. Sections were then stained in haematoxylin for 5 secs, gently washed in tap water for $10 \mathrm{~min}$ and then stained in eosin for approximately 20 sec. Tissue was dehydrated with an increasing alcohol series $(2 \mathrm{x} 80 \%, 2 \mathrm{x}$ $96 \%$ and $2 \mathrm{x} 100 \%$ ethanol). After immersing $2 \mathrm{x}$ for 5 min in Roti ${ }^{\oplus}$ Histol (Carl Roth) slides were mounted in Pertex.

\section{Immunohistochemistry}

Breast cancer surgical specimen was rehydrated after deparaffinizing the embedded tissue sections. Microwave antigen retrieval was performed using unmasking solution (Vector Labs) for $9 \mathrm{~min}$. After a cooling period of at least $15 \mathrm{~min}$, slides were washed in distilled $\mathrm{H}_{2} \mathrm{O}$. Endogenous peroxidase reactivity was blocked by incubating slides in $3 \% \mathrm{H}_{2} \mathrm{O}_{2}$ for $20 \mathrm{~min}$; then, the slides were washed with water and PBS, and incubated with 5\% serum in PBS for $1 \mathrm{~h}$ to block unspecific antibody binding. In all cases, the primary antibody was diluted to a factor of 1:500, goat serum was used for blocking and incubation was for $1 \mathrm{~h}$ at room temperature (RT). The slides were washed three times with PBS to remove unspecifically bound primary antibody. Biotinylated secondary antibody was diluted (1:200) and incubated for 1 hat RT. After washing, VECTASTAIN ${ }^{\star}$ Elite ABC solution (Vector Labs) was added and afterwards slides were incubated with 3, 3'-diaminobenzidine tetrahydrochloride (DAB, Vector Labs) until suitable brown staining is developed. Slides were finally counterstained with hematoxylin and mounted in pertex. The molecular subtypes of breast cancer was determined. The luminal A subtype was defined as $\mathrm{ER}+$ and/or PR+, HER2-. Luminal B subtypes were defined as ER+ and/ or PR+, HER2+. Triple Negative Breast Cancer (TNBC) was defined as ER-, PR-, HER2- and HER2 enriched subtypes was defined as ER-, PR-, HER2+. From a total of 137 breast cancer tissue samples, ER, PR and HER2 test was performed for 87, 50 and 50 formalin fixed paraffin embedded tumor tissue blocks with IHC, respectively. Fifty tissue blocks were analyzed at Martin Luther University (Germany) for HER2, PR and ER with IHC. Only 37 breast cancer tissue blocks were analyzed for ER in Pathology Laboratory at Tikur Anbessa Specialized Hospital, Addis Ababa, Ethiopia. The staining result was interpreted as follows: If the staining of ER and PR scores were over $1 \%$, it was considered as positive. Concerning Her-2/neu over expression, cases showing less than $10 \%$ membrane immunostaining of the tumor cells were scored 0 and cases with faint staining or barely perceptible and incomplete membrane staining in more than $10 \%$ of the tumor cells were scored $1+$; cases with weak to moderate complete membrane staining in more than $10 \%$ of the tumor cells were score $2+$; and cases with strong complete membrane staining in more than $10 \%$ of the tumor cells were scored 3+. All statistical analyses were performed using SPSS version 23. The result was summarized with aid of descriptive statistics, the chi-square and logistic regression testing methods. Only representative pictures of histopathology and immunohistochemistry were demonstrated (Figure 1).

\section{Results}

\section{Socio-demographic characteristics of the study subjects}

A total of 137 confirmed solid breast cancer cases were involved in this study. The age of the study participants ranged from 22 to 100 years (mean and median age were 47 and 46.7, respectively). More than $50 \%$ of the patients were categorized in the age group of 15-40. Sixty percent were in the age group of 41-100. As indicated in Table 1, majority of the patients were from urban areas.

\section{Biological and histopathological description of breast cancer}

Infiltrating ductal carcinoma was the most common type of breast cancer in our study (70\%), followed by lobular carcinoma $(8.5 \%)$. Majority of breast cancer cases (48.5\%) were with stage III at the time

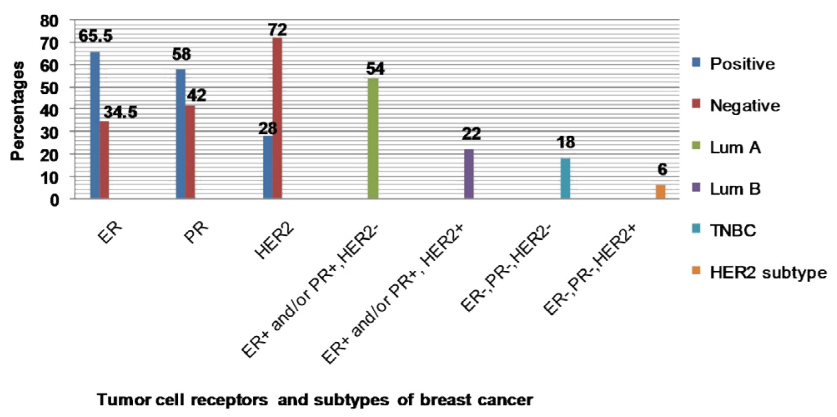

Figure 1: The proportion of breast cancer receptors and subtypes. ER+: Estrogen Receptor Positive; ER-: Estrogen Receptor Negative; PR+ Progesterone Receptor Positive; PR: Progesterone Receptor Negative; HER2+: Human Epidermal Growth Factor Positive; HER2: Human Epidermal Growth Factor Negative; Lum A: Luminal A (ER+ and/orPR+, HER2-); Lum B: Luminal B (ER+ and/or PR+, HER2+); TNBC: Triple Negative (ER-, PR-, HER2) and HER2 subtype (ER-, PR-, HER2+). 
Citation: Shenkutie B, Mekonnen Y, Seifu D, Abebe E, Ergete W, et al. (2017) Biological and Clinicopathological Characteristics of Breast Cancer at Tikur Anbessa Specialized Hospital, Addis Ababa, Ethiopia. J Cancer Sci Ther 9: 755-760. doi:10.4172/1948-5956.1000504

of diagnosis and $44.9 \%$ of the study participants belonged to T2 tumor size $(2-5 \mathrm{~cm})$. Fifty one percent of the study subjects had grade II tumor and $52.3 \%$ of the patients had axillary lymph node metastases (Table 2). Out of 137 cases, 87 cases were analyzed for ER, 50 cases were analyzed for PR and 50 were studied for HER2 with IHC. Totally, $65.5 \%$ were

\begin{tabular}{|c|c|c|}
\hline Characteristics & Frequency & Percent \\
\hline \multicolumn{3}{|c|}{ Age group } \\
\hline $15-40$ & 52 & $40 \%$ \\
\hline $41-100$ & 78 & $60 \%$ \\
\hline \multicolumn{3}{|c|}{ Residence } \\
\hline Urban & 85 & $65.40 \%$ \\
\hline Rural & 45 & $34.60 \%$ \\
\hline \multicolumn{3}{|c|}{ Family history of BC } \\
\hline Yes & 31 & $23.80 \%$ \\
\hline No & 99 & $76.20 \%$ \\
\hline \multicolumn{3}{|c|}{ Alcohol consuming } \\
\hline No & 137 & $100 \%$ \\
\hline \multicolumn{3}{|c|}{ Cigarette smoking } \\
\hline No & 137 & $100 \%$ \\
\hline \multicolumn{3}{|c|}{ BMI } \\
\hline$<18.5$ & 15 & $11.50 \%$ \\
\hline $18.5-24.9$ & 69 & $53.10 \%$ \\
\hline $25-29.9$ & 37 & $28.50 \%$ \\
\hline$\geq 30$ & 9 & $6.90 \%$ \\
\hline \multicolumn{3}{|c|}{ Age at menarche } \\
\hline$\leq 12$ & 19 & $14.60 \%$ \\
\hline$>12$ & 111 & $85.40 \%$ \\
\hline \multicolumn{3}{|c|}{ Age at give first birth } \\
\hline$\leq 20$ & 47 & $45.60 \%$ \\
\hline$>20$ & 56 & $54.40 \%$ \\
\hline \multicolumn{3}{|c|}{ Menstrual status } \\
\hline Pre-menopause & 64 & $49.20 \%$ \\
\hline Post-menopause & 66 & $50.80 \%$ \\
\hline \multicolumn{3}{|c|}{ Give birth } \\
\hline Yes & 103 & $79.20 \%$ \\
\hline No & 27 & $20.80 \%$ \\
\hline \multicolumn{3}{|c|}{ Well-breast fed } \\
\hline Yes & 98 & $95.10 \%$ \\
\hline No & 5 & $4.90 \%$ \\
\hline \multicolumn{3}{|c|}{ OCP used } \\
\hline Yes & 63 & $48.50 \%$ \\
\hline No & 67 & $51.50 \%$ \\
\hline
\end{tabular}

Table 1: Distribution of major risk factors and socio-demographic characteristics for breast cancer cases in Ethiopia.

\begin{tabular}{|c|c|c|}
\hline Histopathological characteristics & Frequency & Percent \\
\hline Infiltrating ductal carcinoma & 91 & 70 \\
\hline Invasive lobular carcinoma & 8 & 6.2 \\
\hline Ductal carcinoma In Situ & 7 & 5.4 \\
\hline Lobular carcinoma In Situ & 11 & 8.5 \\
\hline Mixed (IDC+ILC) & 6 & 4.6 \\
\hline Others & 7 & 5.4 \\
\hline & Tumor size & \\
\hline T1: Tumor $\leq 2$ & 35 & 27.6 \\
\hline T2: Tumor $>2 \mathrm{~cm}, \leq 5 \mathrm{~cm}$ & 57 & 45 \\
\hline T3: Tumor $>5 \mathrm{~cm}$ & 35 & 27.6 \\
\hline & TNM stage & 3 \\
\hline I & 4 & 40 \\
\hline II & 63 & 48.5 \\
\hline III & 52 & \\
\hline
\end{tabular}

\begin{tabular}{|c|c|c|}
\hline IV & 11 & 8.5 \\
\hline \multicolumn{2}{|c|}{ Histological grade } \\
\hline G1 & 17 & 13.1 \\
\hline G2 & 67 & 51.5 \\
\hline G3 & 46 & 35.4 \\
\hline \multicolumn{2}{|c|}{ Lymph node involvement } \\
\hline Axilliary involvement & 68 & 52.3 \\
\hline No involvement 62 & 62 & 47.7 \\
\hline
\end{tabular}

Table 2: Distribution of histopathological types, stage, grade and tumor sizes of $\mathrm{BC}$

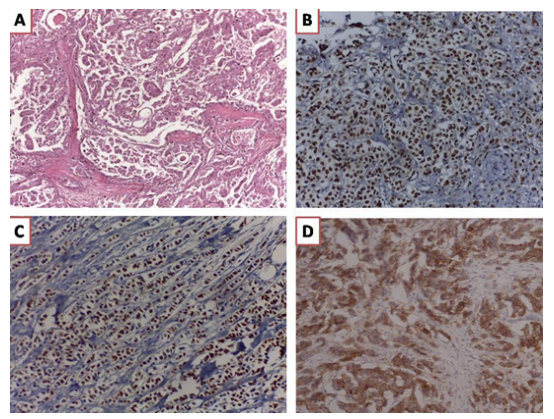

Figure 2: Representative histological and immunohistochemistry figures illustaring invasive ductal carcinoma with infiltrating tumor cells $(A)$, ER+ tumor cells (B) PR+tumor cells with dark nuclear staining (score $3+$ ) and cell membrane staining demonstrating the complete "ring" pattern with a very thick, almost folded outline.

$\mathrm{ER}+, 58 \%$ were $\mathrm{PR}+$ and $28 \%$ were HER2+. Luminal A (54\%) was the most common tumor subtype, followed by luminal B (22\%) and triple negative breast cancer 18\% (Figures 1 and 2).

\section{Selected risk factors association with ER positive breast cancer}

The analysis of some risk factors for breast cancer and their association to ER receptor status was also determined. Based on crude analysis patients with family history of $\mathrm{BC}$ had a lesser likelihood of being $\mathrm{ER}+$ as compared to those patients with no family history of $\mathrm{BC}$ [COR $=0.10$ (95\% CI: $0.028,0.34)]$. This association was consistently significant after adjustment for possible confounding variables using multivariate logistic regression $[\mathrm{AOR}=0.009$ (95\%CI: 0.008, 0.51)]. On the other hand, none of the other risk factors were correlated with the prevalence of ER+ results (Table 3 ).

\section{Discussion}

Biologically, breast cancer is one of the most heterogeneous types of cancer and characterized by several molecular subtypes. As a result, determining clinical outcomes and treatment algorithm is the function of critical analysis of the biological features of the corresponding tumor [23]. In addition, clinico-pathological investigation and assessment of the possible risk factors of breast cancer have important impact on clinical decisions and survival of individual breast cancer patients [24]. The biological and clinico-pathological features also are sometimes patient and geographical-site-specific and vary from one population to the other population $[21,22]$. Therefore, it is important to study the characteristics of a given tumor in depth for improved prognosis of breast cancer patients. To this end, we investigated the biological features, clinico-pathological characteristics and the associated risk factors of breast cancer in Ethiopian patients. The socio-demographic data in our study indicated that the median age of the study subjects was 46.5 years; and $40 \%$ of the subjects were below the age of 40 . In contrast to our findings, the global research experience from the 


\begin{tabular}{|c|c|c|c|c|}
\hline \multirow{2}{*}{ Characteristics } & \multicolumn{2}{|c|}{ ER } & \multirow{2}{*}{ COR $(95 \% \mathrm{Cl})$} & \multirow{2}{*}{ AOR $(95 \% \mathrm{Cl})$} \\
\hline & ER- & ER+ & & \\
\hline \multicolumn{5}{|c|}{ Age } \\
\hline $15-40$ & $15(50)$ & $25(43.9)$ & Reference & Reference \\
\hline $41-100$ & $15(50)$ & $32(56.1)$ & $0.103[0.85,5.201]$ & $0.38[0.44,8.71]$ \\
\hline \multicolumn{5}{|c|}{ BMI } \\
\hline$<18.5$ & $3(10)$ & $7(12.3)$ & Reference & Reference \\
\hline $18.5-24.9$ & $17(56.7)$ & $31(54.4)$ & $0.73[0.78,3.4]$ & $0.434[0.26,4.8]$ \\
\hline $25-30$ & $7(23.3)$ & $17(29.8)$ & $0.96[0.21,5.22]$ & $0.485[0.142,60]$ \\
\hline$>30$ & $3(10)$ & $2(3.5)$ & $0.24[0.3,2.7]$ & $0.139[0.001,2.6]$ \\
\hline \multicolumn{5}{|c|}{ Age at menarche } \\
\hline$\leq 12$ & $1(3.3)$ & $14(24.6)$ & Reference & Reference \\
\hline$>12$ & $29(96.7)$ & $43(75.4)$ & $0.74[0.13,0.85]^{*}$ & $0.161[0.044,2.5]$ \\
\hline \multicolumn{5}{|c|}{ OCP used } \\
\hline Yes & $12(21.1)$ & $30(52.6 \%)$ & $0.022[0.13,0.85]^{*}$ & $0.862[0.23,5.71]$ \\
\hline No & $18(78.9)$ & $27(47.4)$ & Reference & Reference \\
\hline \multicolumn{5}{|c|}{ Age at first birth } \\
\hline$<20$ & $23(76.6)$ & $29(51)$ & Reference & Reference \\
\hline$>20$ & $7(23.3)$ & $28(49)$ & $0.65[0.49,3.06]$ & $0.73[0.27,6.4]$ \\
\hline \multicolumn{5}{|c|}{ Family history of BC } \\
\hline Yes & $9(30)$ & $12(21.1)$ & $0.10(0.028-0.34)^{*}$ & $0.009[0.008,0.51]^{*}$ \\
\hline No & $21(70)$ & $45(78.9)$ & Reference & Reference \\
\hline
\end{tabular}

Table 3: Bivariate and multivariate logistic regression analysis of selected risk factors associated with ER receptor status in breast cancer.

high-income countries normally demonstrated the highest prevalence of breast cancer at an age of 60 and above. Similar studies from the Ghanaian and Indian research groups also indicated the median age of 45 and 49 years, respectively, which is not considerably far away from our result [25]. Furthermore, comparison of the clinico-pathological characteristics of breast cancer between Sudanese and Italian women showed remarkable differences. In line with our findings, breast cancer in Sudanese women is presented at younger age (52 years) than in the Italian women (63 years) [26]. In addition, the median ages of breast cancer patients in Canada, Germany and Belgium are 54, 58 and 58 years, respectively [27-29]. More interestingly, studies from some Asian countries indicated an equivalent median age of the breast cancer patients as in our study [30-32]. Generally, all of the findings in low and middle-income countries, including ours, indicate that breast cancer takes place at notably lower age than the reports from most high-income courtiers. Taken together, the occurrence of breast cancer at lower age in Ethiopian patients is perhaps attributed to several unknown factors. However, it has crucial implications for primary prevention of breast cancer with awareness creation, early diagnosis, providing better health services and availing screening services.

Research has revealed that the lower age groups of breast cancer patients are associated with family history of breast cancer [33]. In our study, only few cases have (23.8\%) family history of breast cancer. The known molecular suspects in familial breast cancer patients are BRCA1, BRCA2, p53, PTEN, CHEK2 and ATM, which are probably the future research areas to be addressed in our population [34]; otherwise there is no evidence currently to link the lower age breast cancer cases with these genes. Our data also indicated that majority of the study subjects were reported to be from urban background. This might not indicate that high prevalence of breast cancer is taking place in urban population. Rather, it could be due to the fact that our urban population has better awareness about breast cancer, advanced education, stronger financial capacity and easier access to diagnostic and treatment services. However, the contribution of lifestyle change, socioeconomic difference and environmental variations in urban population is also remarkable.
Because the urban population has already access to Westernized ways of life and consuming refined junk foods. This is in line with finding from other low-income countries, where larger proportion of breast cancer cases were reported from urban population [35].

Molecular characterization is important to reveal the distinctive biological features of breast cancer. In addition, hormone receptor expression pattern varies from one population to the other population in the globe and crucially important to forecast the prognosis of breast cancer patients. It is also extremely helpful to initiate the right therapeutic approach in breast cancer patients. In current study, we investigated the expression status of ER, PR and HER2 proteins with immuno-histochemistry. Our result showed the expression of ER and PR in $65.5 \%$ and $58 \%$ of the study groups, respectively. About $22 \%$ of the study groups were positive for all the three receptors, while the triple negative breast cancer contributed about $18 \%$ of the cases. The HER2 enriched breast cancer is only $6 \%$. In contrast to our finding, Nissan et al. found no significant difference in ER and PR expression in Palestinian women (78\% being ER+ and 72\% PR+ [36]. Studies in other breast cancer patients in middle income countries like India and South Korea indicated relatively higher prevalence of ER+ breast cancer [37,38]. Similarly, the assessment of breast cancer hormone receptors status in 60 patients in Tanzania indicated the expression of ER and PR in $33 \%$ and $18 \%$ of the cases [39], respectively. This is lower than the current finding in Ethiopian breast cancer patients. Other study in 120 patients in Kenya revealed 33\% ER+/PR+ and 24\% ER+(43); which is still far lower than our finding. Interestingly, the Kenyan study indicated absence of any association between ER/PR positivity and stage, age, parity, menopausal status, or node metastases [40]. The lower proportion of hormonal receptor positive breast cancer cases in the above two studies from the mentioned East African countries and the relatively higher expression of these receptors in Ethiopian breast cancer patients indicated determining the receptor statuses in breast cancer patients before initiating therapeutic options is of paramount clinical significance. In addition, the currently available standard treatment protocols in use today relies on ER, PR, and Her2 receptor 
expression status by the breast cancer cells. However, it is noteworthy to mention that there is discrepancy in the expression pattern of the hormone receptor status in the global breast cancer. Clear justification for the observed variation can be uncovered by investigating the genetic profiles of breast cancer in future.

In terms of the prevalence of breast cancer subtypes, the current finding revealed that luminal A was the most prevalent (54\%), followed by luminal B (22\%), triple negative (18\%) and Her2 subtypes (6\%). This disagrees with other studies from India where $34 \%$ of the cases were luminal A, followed by TNBC (25\%); whereas luminal B and Her2/neu subtypes had same prevalence (18\% of each) [41]. Studies in Ghana indicated $25.6 \%$ of luminal A, $12.2 \%$ of luminal B and $49.9 \%$ of TNBC (27). The reasons for these difference results might be due to several reasons like variation in sampling size, method, period and protocol, in addition to reproductive factors, environmental and genetic factors $[13,42]$. We have also investigated the histological characteristics, the pathological stages and grades of breast cancer in the study subjects. The result showed that majority of the study groups were diagnosed at advanced stage of the disease. About $48.5 \%$ was stage III and $51 \%$ of the study subjects had grade II tumor and $52.3 \%$ of the patients had axillary lymph node metastases. Furthermore, morphological investigation indicated that infiltrating ductal carcinoma is the predominant histological type in our study (70\%). This is in agreement with breast cancer histological investigations in many low and middleincome countries in Africa and Asia [6,43-45]. This is mostly due to the fact that most of cancer cases in these countries are presented at advanced stages of the diseases where the patient cannot benefit from the treatment approach. This is, in turn, due to lack of awareness of the population about breast cancer, absence of well-structured breast cancer prevention programs like screening programs, and unavailability of advanced pathological diagnostic services in these regions. Therefore, awareness creation among the population, providing advanced cancer care services and strengthening cancer research in these countries is urgently needed.

\section{Conclusion}

The findings from this study indicated that a significant number of the cancer cases were Estrogen and Progestrone recepter positive. Hence, in a resource poor setting like Ethiopia, the use of anti-estrogens (like tamoxifen) in treatment of breast cancer cases with undetermined receptor status could be helpful as these drugs are relatively easily available. Except with the application of immunohistochemistry and other molecular techniques it is not possible to predict the breast cancer phenotypes with the aid of the socio-demographic data of the patients. Finally, it should be noted that the age distribution of breast cancer cases in Ethiopian patents suggests the need to make available, screening programs like mammography for women above 20 years with special emphasis on women 35 and above.

\section{Acknowledgments}

We are grateful to all female breast cancer patients who participated in this study and who generally shared their experiences and information with us. We also would like to acknowledge those technical staff who participated in the study. Finally, we are thankful to Addis Ababa University postgraduate program for financial support provided to this study.

\section{References}

1. DeSantis C, Siegel R, Bandi P, Jemal A (2011) Breast cancer statistics. CA Cancer J Clin 61: 409-418.

2. Eisemann N, Waldmann A, Katalinic A (2013) Epidemiology of breast cancer current figures and trends. Geburtsh Frauenheilk 73: 130-135.
3. Weigelt B, Baehner FL, Reis-Filho JS (2010) The contribution of gene expression profiling to breast cancer classification, prog-nostication and prediction: A retrospective of the last decade. J Pathol 220: 263-280.

4. Abramson VG, Lehmann BD, Ballinger TJ, Pietenpol JA (2015) Subtyping of triple-negative breast cancer: Implications for therapy. Cancer 121: 8-16.

5. Pal T, Permuth-Wey J, Holtje T, Sutphen R (2004) BRCA1 and BRCA2 mutations in a study of African American breast cancer patients. Cancer Epidemiol Biomarkers Prev. 13:1683-1686.

6. Chopra B, Kaur V, Singh K, Verma M, Singh S et al. (2014) Age shift: Breast cancer is occurring in younger age group- Is it true? Clin Ca Invest Cont 3: 526-529.

7. Spitale A, Mazzola P, Soldini D, Mazzucchelli L, Bordoni A (2009) Breast cance classification according to immunohistochemical markers: clinicopathologic features and short-term survival analysis in a population-based study from the South of Switzerland. Ann Oncol. 20: 628-635.

8. Reis-Filho JS, Weigelt B, Fumagalli D, Sotiriou C (2010) Molecular profiling: Moving away from tumor philately. Sci Transl Med 2: 47

9. Morikawa A, Henry NL (2015) Palbociclib for the treatment of estrogen receptor-positive, HER2-negative metastatic breast cancer. Clin Cancer Res 21: 3591-3596.

10. Dai X, Chen A, Bai Z (2014) Integrative investigation on breast cancer in ER, PR and HER2-defined subgroups using mRNA and miRNA expression profiling. Sci Rep 4: 6566.

11. Amend K, Hicks D, Ambrosone CB (2013) Breast cancer in African-American women: Differences in tumor biology from European-American women. Cancer Res 66:8327-8330.

12. Bairati I, Jobin E, Fillion L, Larochelle M, Vincent L (2007) Determinants of delay for breast cancer diagnosis. Cancer Detect Prev 31: 323-331.

13. Kantelhardt EJ, Zerche P, Mathewos A, Trocchi P, Addissie A (2014) Breast cancer survival in Ethiopia: A cohort study of 1,070 women. Int J Cancer 135: 702-709.

14. Burson AM, Soliman AS, Ngoma TA Mwaiselage J, Ogweyo P, et al. (2010) Clinical and epidemiologic profile of breast cancer in Tanzania. Breast Dis 31 33-41.

15. Farmer P, Frenk J, Knaul FM, Lawrence NS, Alleyne G, et al. (2010) Expansion of cancer care and control in countries of low and middle income: a call to action The Lancet 376: 1186-1193.

16. Galukande V, Wabinga $H$, Mirembe $F$ (2015) Breast cancer survival experiences at a tertiary hospital in sub-Saharan Africa: a cohort study. World J Surg Onco 13: 220

17. Sighoko D, Kamate B, Traore C, Malle B, Coulibaly B, et al (2013) Breast cancer in pre-menopausal women in West Africa: Analysis of temporal trends and evaluation of risk factors associated with reproductive life. Breast 22: 828-835.

18. Robinson D, Bell J, Moller H, Salman A (2006) A 13-year follow-up of patients with breast cancer presenting to a District General Hospital breast unit in southeast England. Breast 15: 173-180.

19. Brinton LA, Sherman ME, Carreon JD, Anderson WF (2008) Recent trends in breast cancer among younger women in the United States. J Natl Cancer Inst 100: $1643-1648$

20. Sineshaw HM, Gaudet M, Ward EM, Flanders WD, Desantis C, et al. (2014) Association of race/ethnicity, socioeconomic status, and breast cance subtypes in the National Cancer Data Base (2010-2011). Breast Cancer Res Treat 145: 753-763.

21. Huo D, Ikpatt F, Khramtsov A, Dangou JM, Nanda R, et al. (2009) Population differences in breast cancer: survey in indigenous African women reveals overrepresentation of triple-negative breast cancer. J Clin Oncol 27: 4515-4521.

22. Andre F, Pusztai L (2006) Molecular classification of breast cancer: implications for selection of adjuvant chemotherapy. Nat Clin Prac Oncol 3: 621-632.

23. Jamil K, Kumar K, Fatima HS, Rabbani S, Kumar R, et al. (2007) Clinical studies on hormonal status in breast cancer and its impact on quality of life (QOL). JCST 1: 2

24. Rakha EA, Reis-Filho JS, Baehner F, Dabbs DJ, Decker T, et al. (2010) Breast cancer prognostic classification in the molecular era: the role of histological grade. Breast Cancer Res 12: 207 
Citation: Shenkutie B, Mekonnen Y, Seifu D, Abebe E, Ergete W, et al. (2017) Biological and Clinicopathological Characteristics of Breast Cancer at Tikur Anbessa Specialized Hospital, Addis Ababa, Ethiopia. J Cancer Sci Ther 9: 755-760. doi:10.4172/1948-5956.1000504

25. Seshie B, Adu-Aryee NA, Dedey F, Calys-Tagoe B, Clegg-Lamptey JN (2015) Retrospective analysis of breast cancer subtypes based on ER/PR and HER2 status in Ghanaian patients at the KorleBu Teaching Hospitals, Ghana. BMC Clin Pathol 15: 14

26. Awadelkarim K, Arizzi C, Elamin E, Hamad H, De Blasio P, et al. (2008) Pathological, clinical and prognostic characteristics of breast cancer in Central Sudan versus Northern Italy: Implications for breast cancer in Africa. Histopatholog 52: 445-456.

27. Thavendiranathan $\mathrm{P}$, Abdel-Qadir H, Fischer HD, Camacho X, Amir E et al. (2016) Breast cancer Therapy-Related Cardiac dysfunction in adult women treated in routine clinical practice: A population-based cohort study. J Clin Oncol 34: 1833-1835.

28. Rezai M, Kellersmann S, Knispel S, Lax H, Kimmig R (2015) Translating the concept of intrinsic subtypes into an oncoplastic cohort of more than 1000 patients- predictors of recurrence and survival. Breast 24: 384-390.

29. Brouckaert O, Schoneveld A, Truyers C, Kellen E, Van Ongeval C, et al. (2015) Breast cancer phenotype, nodal status and palpability may be useful in the detection of over diagnosed screening-detected breast cancers. Ann.Oncol 24: 1847-1852.

30. Pourzand A, Fakhree MB, Hashemzadeh S, Halimi M, Daryani A (2011) Hormone receptor status in breast cancer and its relation to age and other prognostic factors. Breast Cancer (Auckl) 5: 87-92

31. Rudat V, El-Sweilmeen H, Fadel E, Brune-Erber I, Nour AA, et al. (2012) Age of 40 years or younger is an independent risk factor for locoregional failure in early breast cancer: A single-institutional analysis in Saudi Arabia. J. Oncol 12: 10.

32. Thangjam S, Laishram RS, Debnath K (2016) Breast carcinoma in young females below the age of 40 years: A histopathological perspective. South Asian J Cancer 3: 97-100.

33. Ghiasvand R, Adami H, Harirchi I, Akrami R, Zendehdel K (2014) Higher incidence of premenopausal breast cancer in less developed countries; myth or truth? BMC Cancer 14: 343.

34. Holstege $H$, Horlings HM, Velds A, Langerod A, Børresen-Dale LA, et al (2010) BRCA1-mutated and basal-like breast cancers have similar aCGH profiles and a high incidence of protein truncating TP53 mutations. BMC cancer 10: 654 .
35. Sandhu DS, Sandhu S, Karwasra RK, Marwah S (2010) Profile of breast cancer patients at a tertiary care hospital in North India. Indian J Cancer 47: 16-22.

36. Nissan A, Spira RM, Hamburger T, Badrriyah M, Prus D (2004) Clinical profile of breast cancer in Arab and Jewish women in the Jerusalem area. Am J Surg 188: $62-67$.

37. Alfred R, Chin SN, Williams E, Walters C, Barton EN, et al. (2014) The prevalence and significance of oestrogen receptor (ER) positivity in breast cancer at the University Hospital of the West Indies, Jamaica. West Indian Med J 6: 795-801.

38. Chakrabarti S, Karmarker R, Barui G, Maity PK, Bandyopadhyay, et al. (2012) Prevalence of known prognostic factors in female breast carcinoma including oestrogen receptor, progesterone receptor and HER-2/neu status. J Indian Med Assoc 110: 876-879.

39. Brinton LA, Figueroa JD, Awuah B, Yarney J, Wiafe S (2014) Breast cancer in Sub-Saharan Africa: opportunities for prevention. Breast Cancer Res Treat 144: $467-478$.

40. Bird PA, Hill AG, Houssami N (2008) Poor hormone receptor expression in East African breast cancer: Evidence of a biologically different disease? Ann Surg Oncol 15: 1983-1988.

41. Kumar N, Patni P, Agarwal A, Khan MA, Parashar N (2015) Prevalence of molecular subtypes of invasive breast cancer: A retrospective study. Med J Armed Forces India 71: 254-258.

42. Chu CK, Anderson FW, Fritz A, Rles GA Brawley WO (2001) Frequency distributions of breast cancer characteristics classified by estrogen receptor and progesterone receptor status for eight racial/ethnic groups. Cancer 92: 3745 .

43. Mvila GL, Postema S, Marchal G, Limbergen EV, Verdonck F, et al. (2014) From the set-up of a screening program of breast cancer patients to the identification of the first BRCA mutation in the DR Congo. BMC Public Health 14: 759.

44. Akarolo-Anthony SN, Ogundiran TO, Adebamowo CA (2010) Emerging breas cancer epidemic: Evidence from Africa. Breast Cancer Res 12: S8.

45. Pakseresht S, Ingle GK, Garg S, Sarafraz N (2014) Stage at diagnosis and delay in seeking medical care among women with breast cancer, Delhi. Iran Red Crescent Med J 16: e14490. 